\title{
Incidence of severe acute renal failure in adults: results of a community based study
}

\author{
T G Feest, A Round, S Hamad
}

\begin{abstract}
Objective-To determine the age related incidence of severe acute renal failure in adults in two health districts in England.

Design-Prospective study of patients identified as having severe acute renal failure within a two year period; subsequent monitoring of outcome for a further two years.

Setting-Two health districts in Devon.

Subjects-Those adults in a population of $\mathbf{4 4 4 9 7 1}$ who developed severe acute renal failure (serum creatinine concentration $>500 \mu \mathrm{mol} / /$ ) for the first time during two years, with subsequent fall of the serum creatinine concentration below the index value.

Main outcome measures and results-125 adults (140 per million total population yearly, 172 per million adults) developed severe acute renal failure, of whom $90(72 \%)$ were over 70 . Age related incidence rose from 17 per million yearly in adults under 50 to 949 per million yearly in the 80-89 age goups. In 31 patients (25\%) the cause was prostatic disease, which was related to a good prognosis $(84 \%$ (26) alive at three months). Overall survival was 54\% (67) at three months and 34\% (42) at two years and was not significantly age related. 18 per million total population yearly ( 22 per million adult population) received acute dialysis. Referral rate for specialised opinion was 51 per million total population yearly with an estimated appropriate referral rate of 70 per million per year.
\end{abstract}

Conclusions-The incidence of severe acute renal failure in the community is at least twice as high as the incidence reported from renal unit based studies. Prostatic disease, a preventable and treatable problem, is the most common cause. Survival figures indicate that age alone should not be a bar to specialist referral or treatment.

\section{Introduction}

There seems to have been little improvement in survival in patients with acute renal failure in the past 20 years. ${ }^{12}$ This has often been attributed to changes in the characteristics of the population studied. ${ }^{23} \mathrm{Com}-$ parison among studies is hampered by use of different definition criteria, selection criteria, or population base. ${ }^{2}$ Data collected from a renal unit do not give a true reflection of need as general practitioner and consultant referral rates may be influenced by their perceptions of the services available. ${ }^{45}$ This study looks at true population incidence rates, referral rates, and survival in adults, particularly with respect to age and underlying diagnosis. An estimate of workload implications is made.

\section{Patients and methods}

The study covered two health districts with a combined population of 444971 each with a stable population and negligible cross boundary flow. Each district had only one biochemical pathology laboratory, which always measured serum creatinine concentration whenever electrolyte or other biochemical investigations were requested. The laboratories carried out all work for general practitioners, National Health Service, and private hospitals in the area.

Over two years starting 1 January 1986 all serum creatinine concentration measurements were scrutinised and any patient with a concentration greater than $500 \mu \mathrm{mol} / /$ identified. The notes were studied subsequently, or in cases of blood tests initiated by general practitioners these doctors were contacted for further information. Patients not living in the two health districts were excluded. The last follow up was made on 1 March 1990. Patients living within the defined geographical area were considered to have severe acute renal failure if the serum creatinine concentration rose above $500 \mu \mathrm{mol} / \mathrm{l}$ for the first time and then returned to below that level and remained there or if the patient died during the acute illness and the history or necropsy confirmed acute renal failure. Patients whose serum creatinine concentration did not subsequently fall below $500 \mu \mathrm{mol} / /$ were defined as having chronic renal failure; those in whom acute renal failure was part of any underlying terminal disease (usually malignant) were also excluded. There was no cardiac surgery unit in the two districts studied. This definition would not identify severe renal failure in children. Throughout the paper the term adult means over the age of 15 .

Haemoglobin, serum potassium, and serum bicarbonate concentrations and the presence or absence of oliguria (less than $400 \mathrm{ml}$ urine in 24 hours) were ascertained retrospectively.

Confidence intervals for incidence rates were assessed by reference to the Poisson distribution. Comparison between outcomes was performed by $\chi^{2}$ test with Yates's correction. The population estimates and distribution by age were taken from the Office of Population Censuses and Surveys report for $1988 .^{\circ}$

\section{Results}

Altogether 125 patients were identified during the two years, giving an overall incidence of severe acute renal failure of 140.5 (95\% confidence interval 117.0 to $172 \cdot 0)$ cases per million total population yearly and an annual incidence of $172.5(144 \cdot 1$ to $205 \cdot 5)$ cases per million adult population.

\section{AGE AND SEX INCIDENCE}

Ninety $(72 \%)$ patients were over 70 , although only $14 \%$ of the population studied were above this age. The incidence of severe acute renal failure increased with age from $17 \cdot 1$ cases per million population per year in adults under 50 to 949 cases per million per year in the 80 to 89 age group (table I). A significant rise with age remained even when prostatic disease (which is largely associated with age) was excluded from the analysis.

Corresponde 
There was a significant difference in incidence between the sexes, 90 men and 35 women being identified $\left(x^{2}=29 \cdot 16 ; \mathrm{df}=1\right)$. The annual incidence of severe acute renal failure was $259.4(208.6$ to 318.9$)$ cases per million adult males and $92.6(64.5$ to $128 \cdot 8)$ cases per million adult females $(p<0.001)$. The difference remained significant ( 59 men, 35 women; $\chi^{2}=8.39, \mathrm{df}=1, \mathrm{p}<0.01$ ) when cases of prostatic disease were excluded.

Survival at either three months or two years was not significantly related to age $\left(\chi^{2}\right.$ for trend $=0.000$, $p=0.984 ;$ and $0.03, p=0.863$ respectively). The apparent higher percentage survival rate at two years in the under 50 group (table II) and in those over 80, even after exclusion of patients with prostatic disease, was not significant $\left(X^{2}\right.$ for trend $=0.132$ and 0.49 respectively).

\section{DIAGNOSIS}

The largest single category of patients was those with prostatic disease $(n=31)$, which included both benign and malignant prostatic obstruction. More than one in three men over 70 with acute renal failure had prostatic disease as a cause (27 out of 72 ). Medical diagnoses covered a range of conditions, including dehydration (11 patients), sepsis (13), intrinsic renal disease (seven), and haematological disease (eight), or a combination of these in a few cases. Cardiovascular disease was defined as such when the renal failure was secondary to an acute event in the cardiovascular system, usually myocardial infarction. Obstruction covered all mechanical obstruction to the urinary tract, excluding prostatic disease. Most patients in this category had renal stones. Surgical causes were mostly postoperative but some were in the category of acute surgical admissions. Results are given in table III.

Diagnosis influenced survival both at three months and at two years (table IV). Prostatic disease was significantly associated with good survival and cardiovascular disease with poor survival. Patients with prostatic disease were removed from the survival figures to see if they were a confounder for age; although overall survival was worse in the remainder, there was still no association with age (table II).

RECOVERY OF RENAL FUNCTION

Recovery of renal function was examined in patients

TABLE I-Age related annual incidence of severe acute renal failure in adults

\begin{tabular}{|c|c|c|c|c|c|c|}
\hline \multirow[b]{2}{*}{$\begin{array}{l}\text { Age group } \\
\text { (years) }\end{array}$} & \multicolumn{3}{|c|}{ All } & \multicolumn{3}{|c|}{ Excluding prostatic obstruction } \\
\hline & $\begin{array}{l}\text { No of } \\
\text { cases }\end{array}$ & $\begin{array}{c}\text { Rate per } \\
\text { million } \\
\text { population } \\
\text { yearly }\end{array}$ & $\begin{array}{c}95 \% \\
\text { Confidence } \\
\text { interval }\end{array}$ & $\begin{array}{l}\text { No of } \\
\text { cases }\end{array}$ & $\begin{array}{c}\text { Rate per } \\
\text { million } \\
\text { population } \\
\text { yearly }\end{array}$ & $\begin{array}{c}95 \% \\
\text { Confidence } \\
\text { interval }\end{array}$ \\
\hline $16-49$ & 7 & $17 \cdot 1$ & 6.9 to 35.2 & 7 & $17 \cdot 1$ & 6.9 to 35.2 \\
\hline $50-59$ & 8 & $82 \cdot 7$ & $35 \cdot 1$ to $163 \cdot 3$ & 8 & $82 \cdot 7$ & 35.1 to 163.3 \\
\hline $60-69$ & 20 & 185.9 & 113.5 to 288.4 & 16 & 148.9 & $84 \cdot 6$ to $242 \cdot 0$ \\
\hline $70-79$ & 53 & $660 \cdot 3$ & $493 \cdot 3$ to $864 \cdot 6$ & 39 & 485.9 & 345.0 to 666.5 \\
\hline $80-89$ & 35 & $949 \cdot 0$ & 661.6 to 1323.1 & 23 & 623.6 & 395.9 to 935.4 \\
\hline$>89$ & 2 & NC & NC & 1 & NC & NC \\
\hline
\end{tabular}

$\mathrm{NC}=$ Not calculated. million adult population yearly $=172 \cdot 4(95 \%$ confidence interval $144 \cdot 1$ to $205 \cdot 5)$.

TABLE II-Age related survival of patients with severe acute renal failure

\begin{tabular}{|c|c|c|c|c|c|c|}
\hline \multirow[b]{2}{*}{$\begin{array}{l}\text { Age group } \\
\text { (years) }\end{array}$} & \multicolumn{2}{|c|}{ No of cases } & \multicolumn{2}{|c|}{$\begin{array}{l}\text { No (\%) of patients alive } \\
\text { at three months }\end{array}$} & \multicolumn{2}{|c|}{$\begin{array}{c}\text { No (\%) of patients alive } \\
\text { at two years }\end{array}$} \\
\hline & All & $\begin{array}{l}\text { Excluding } \\
\text { prostatic } \\
\text { obstruction }\end{array}$ & All & $\begin{array}{l}\text { Excluding } \\
\text { prostatic } \\
\text { obstruction }\end{array}$ & All & $\begin{array}{l}\text { Excluding } \\
\text { prostatic } \\
\text { obstruction }\end{array}$ \\
\hline $0-49$ & 7 & 7 & $5(71)$ & $5(71)$ & $5(71)$ & $5(71)$ \\
\hline $50-59$ & 8 & 8 & $4(50)$ & $4(50)$ & $2(25)$ & $2(25)$ \\
\hline $60-69$ & 20 & 16 & $9(45)$ & $7(44)$ & $5(25)$ & $3(19)$ \\
\hline $70-79$ & 53 & 39 & $26(49)$ & $13(33)$ & $15(28)$ & $6(15)$ \\
\hline $80-89$ & 35 & 23 & $23(66)$ & $13(57)$ & $15(43)$ & $9(39)$ \\
\hline$>89$ & 2 & 1 & 0 & 0 & 0 & 0 \\
\hline Total & 125 & 94 & $67(54)$ & $42(45)$ & $42(34)$ & $25(27)$ \\
\hline
\end{tabular}

TABLE III-Diagnoses in patients with severe acute renal failure

\begin{tabular}{lcc}
\hline & $\begin{array}{c}\text { No (\%) of } \\
\text { patients }\end{array}$ \\
\hline Cardiovascular & $16(13)$ \\
Surgery & $17(14)$ \\
Other obstetric & $14(11)$ \\
Prostatic obstruction & & $31(25)$ \\
Medical & $13(31)$ & \\
$\quad$ Miscellaneous & $32(34)$ \\
Toxins & $3(7)$ & \\
$\quad$ Renal & $7(17)$ & \\
$\quad$ Holume loss & $11(26)$ & \\
Unknown & $8(19)$ & $5(4)$ \\
\hline Total & & $125(100)$ \\
\hline
\end{tabular}

TABLE IV-Survival by diagnostic category

\begin{tabular}{lccc}
\hline Diagnosis & $\begin{array}{c}\text { No of } \\
\text { cases }\end{array}$ & $\begin{array}{c}\text { No (\%) of patients } \\
\text { alive at three months }\end{array}$ & $\begin{array}{c}\text { No (\%) of patients } \\
\text { alive at two years }\end{array}$ \\
\hline $\begin{array}{l}\text { Medical } \\
\text { Prostatic disease }\end{array}$ & 42 & $22(52)$ & $15(36)$ \\
Surgical (excluding & 31 & $26(84)^{\star}$ & $17(55) \dagger$ \\
$\quad$ prostate) & 17 & $6(35)$ & $5(29)$ \\
Obstruction & 14 & $9(64)$ & $3(21)$ \\
Cardiovascular event & 16 & $0^{\star}$ & $0^{\star}$ \\
Unknown & 5 & $4(80)$ & $2(40)$ \\
\hline${ }^{\star} \chi^{2}=16.02$, df $=5 ; p<0.01+\chi^{2}=10.38, d f=5 ; p<0.01$ &
\end{tabular}

who survived more than three months. The lowest recorded serum creatinine concentration was used, and figures were available for 59 of the 67 patients. In only $21(36 \%)$ did the serum creatinine concentration fall to normal $(<110 \mu \mathrm{mol} / \mathrm{l})$. In all five patients under 50 creatinine values returned to normal. In 12 patients $(20 \%)$ the serum creatinine concentration did not return to below $300 \mu \mathrm{mol} / 1$; one of these had a subsequent deterioration in renal function and two years later had started dialysis.

\section{PROGNOSTIC FACTORS}

Retrospective analysis of prognostic factors at presentation identified oliguria as the only factor significantly associated with death at three months. Of patients with oliguria, $23 \%$ (13/57) survived more than three months compared with $63 \%(25 / 40)$ of the others $\left(\chi^{2}=17 \cdot 14, \mathrm{df}=1, \mathrm{p}<0 \cdot 001\right)$. Hyperkalaemia $\left(\chi^{2}=0 \cdot 18\right.$, $\mathrm{df}=1, \mathrm{p}<0 \cdot 75)$, degree of acidosis $\left(\chi^{2}=2 \cdot 05, \mathrm{df}=1\right.$, $p<0 \cdot 25$ ), and the presence of anaemia (haemoglobin concentration $\left.<110 \mathrm{~g} / 1 ; \chi^{2}=0.79, \mathrm{df}=1, \mathrm{p}<0.5\right)$ were not related to survival. Fifty nine patients $(47 \%)$ were anaemic at first presentation.

\section{REFERRAL PATTERNS AND WORKLOAD}

Only 45 patients (36\%) were referred for a nephrological opinion, an annual rate of 51 (95\% confidence interval 32.8 to 60.2 ) per million total population, or $62 \cdot 1(45 \cdot 3$ to $83 \cdot 1)$ per million adults. Only $18 \%$ of patients $(5 / 28)$ living in the district with no renal unit were referred compared with $41 \%(40 / 97)$ of those living in the Exeter district $\left(p<0.05, X^{2}=6.3, d f=1\right.$; $p<0.02$ ). On scrutinising the notes of the 80 patients not referred for a specialist opinion we concluded that a nephrological opinion might have helped management in 17 cases. This subjective review gives a potential referral rate to nephrologists of 70 patients (95\% confidence interval 53.4 to 89.3 ) per million population per year or $85.4(65.5$ to $109 \cdot 5)$ per million adults per year.

Sixteen patients received acute dialysis or haemofiltration-a rate of 18 cases $(10 \cdot 3$ to $29 \cdot 2)$ per million population per year or $22.1(12.6$ to 35.8$)$ per million adults per year; eight of these patients survived three months and four survived two years.

Of the 16 dialysed patients, seven had sepsis as a major contributory factor to their acute renal failure; only one survived more than three months. Seven of the nine dialysed patients without sepsis survived longer than this $(p=0 \cdot 04$; Fisher's exact test). 


\section{Discussion}

A problem in studying acute renal failure is the lack of a clearly agreed definition. ${ }^{2}$ Our definition is pragmatic, chosen such that the renal failure is severe enough to influence patient survival and morbidity, may need specialist advice, and may have workload and planning implications. The definition is not equivalent to acute tubular necrosis; indeed, the study emphasises that many other renal insults cause severe acute renal failure. The incidence found was probably an underestimate of true community incidence as the protocol did not pick up those people in whom, for whatever reason, the clinicians caring for them did not measure the serum electrolyte values. There is likely to be an excess of elderly people in this category. In addition, cardiac surgery was not carried out in the two districts studied. Any renal unit serving a district with cardiac surgery facilities would have significantly more patients developing acute postoperative renal failure.

Our study also underestimates the incidence of acute renal failure in one other way. Some patients who present with acute renal disease as an emergency to a renal unit, often with forms of rapidly progressive glomerulonephritis, do not subsequently recover renal function. Although acute and an emergency at presentation, they do not fall within the definition used here of acute renal failure as they do not have adequate recovery.

Included in our definition were people who had mild chronic renal failure who suffered an acute or chronic deterioration of function and then made some recovery. It is unlikely that many had progressive chronic renal failure, as at two year follow up only one patient had subsequently deteriorated and needed long term dialysis. We do not, however, have the diagnoses of all patients who died between three months and two years, and it is possible that chronic renal disease was a factor in some of these.

With one exception ${ }^{7}$ previous studies of acute renal failure were renal unit based ${ }^{1-38-13}$ and did not include those patients who were not referred for specialist opinion. Such studies do not give a true reflection of population needs, nor may the clinical indices used to predict survival ${ }^{9}$ or estimates of prognosis ${ }^{10}$ be applicable in the wider population of patients with severe acute renal failure. The influence of age on survival is not clear; some studies $^{812}$ show an adverse effect whereas others ${ }^{7011}$ do not.

\section{EFFECTS OF AGE AND SEX}

The lack of effect of age on survival in our study has significant implications for workload as it confounds the view that treatment of elderly people with severe acute renal failure is not indicated. Furthermore, as the numbers of elderly people in the population increase so will the incidence of severe acute renal failure. Our current estimate of 70 cases per million population per year is certainly the minimum for the reasons described. This study shows that some patients are not referred for specialist opinion, the shortfall being mainly among elderly people. If other practitioners' perception of the value of treatment of severe acute renal failure in elderly people changes nephrologists workload will increase. The study also confirms that referral rates are lower in areas where there is no local renal unit nearby.

The excess of male patients was unexplained. Although this excess seems to be a constant feature of all studies of acute renal failure, ${ }^{17-14}$ it has not been commented on before. This study shows that prostatic disease explains only part of the increased male incidence. Sacks et al highlighted the importance of prostatic disease as a preventable and treatable cause of renal failure. ${ }^{15}$ The high incidence of prostatic obstruction in this study emphasises that finding a raised creatinine concentration in any male necessitates careful palpation of the abdomen and prostate. Many undiagnosed patients with prostatic obstruction were referred to the renal unit.

Other studies have also shown that oliguria ${ }^{1011}$ and sepsis $^{8913}$ are associated with a poor outcome. The finding of anaemia at presentation in almost half our patients is worth noting as it is still widely taught that this is an indicator of chronic rather than acute renal failure. ${ }^{16}$ These results show it has little discriminatory value.

Most patients did not make a full renal recovery. In some cases this is probably because the cause of acute renal failure itself was associated with a degree of permanent damage, and elderly people (who formed the bulk of our patients) may have less renal reserve and be less able to make a full recovery after an acute insult. Kjellstrand et al showed that incomplete recovery from acute tubular necrosis was common in patients over $55,{ }^{17}$ the age range of most of our patients. There will also be a large number of people with already impaired renal function as these are probably more susceptible to further insults than people with normal, healthy kidneys. Whatever the reason for the failure of full recovery sufficient patients remain with significant renal impairment that mid-term to longterm follow up of patients after an episode of severe acute renal failure is indicated.

This prospective community based study has given estimates of the incidence of acute renal failure in an unselected population, indicates a potential workload for renal services, and highlights the importance of preventable and treatable acute renal failure in the form of prostatic disease.

This work is part a project initiated by a subcommittee of the Renal Association set up to study the provision of renal services in the United Kingdom. The study was supported by a grant from the Medical Research Council. We thank Elizabeth Boylan for help in collecting the initial data, all the doctors from the two health districts who agreed to their patients being assessed, and the pathology laboratories for their cooperation.

1 Swann RC, Merrill JP. The clinical course of acute renal failure. Medicine 1953;32:215-92.

2 Buktus ED. Persistent high mortality in acute renal failure. Are we asking the right questions? Arch Intern Med 1983;143:209-12.

3 Lazarus JM. Acute renal failure. Intensive Care Medicine 1988;12:61-3,

4 Kerssens JT, Groenewegen PP. Referrals to physiotherapy: the relationship between the number of referrals, the indication for referral and the inclination to refer. Soc Sci Med 1990;30:797-804.

5 Boardman AP, Bowes N, Craig TK. General practitioner referrals to an ambulatory psychiatric service. The effects of establishing an ease of access service. Int $\mathcal{F}$ Soc Psychiatry 1988;34:172-83.

6 Office of Population Censuses and Surveys. Report. London: HMSO, 1988.

7 Kaufman J, Dhakal M, Patel B, Hownburger R. Community acquired acute renal failure. Am f Kidney Dis 1991;17:191-8.

8 Turney JH, Marshall DH, Brownjohn AM, Ellis CM, Parsons FM. The evolution of acute renal failure 1956-1988. Qf Med 1990;74:83-104.

$9 \mathrm{Lohr} \mathrm{JW}, \mathrm{McFarlane}$ MJ, Gratham J. A clinical index to predict survival in acute renal failure patients requiring dialysis. Am $\mathcal{F}$ Kidney Dis 1988;11: 254-9.

10 Lamiere N, Matthys R, Vanholder MR, de Keyser K, Pauwels $W$, Nachtergaele $\mathrm{H}$, et al. Causes and prognosis of acute renal failure in elderly patients. Nephrol Dial Transplant 1987;2:316-22.

11 Rasmussen $\mathrm{HH}$, Ibels LS. Acute renal failure--multivariate analysis of cause and risk factors. $A m \mathcal{F}$ Med 1982;73:211-8.

12 Abraham G, Gupta RK, Senthilselvan A, van der Meulen J, Johny KV. Cause and prognosis of acute renal failure in Kuwait-a 2 year prospective study. $f$ Trop Med Hyg 1989;92:325-9.

13 Kennedy AC, Burton JA, Luke RG, Briggs JD, Lindsay RM, Allison MEM et al. Factors affecting the prognosis in acute renal failure. $Q f \mathrm{Med}$ 1973;47:73-86.

14 Reynolds GA, Chitnis JG, Roland MO. General practitioner outpatient referrals: do good doctors refer more patients to hospital? BMF 1991;302: $1250-2$

15 Sacks SH, Aparicio SAJR, Bevan A, Oliver DO, Will EJ, Davison AM. Late renal failure due to prostatic outflow obstruction: a preventable disease. renal failure due to

16 Oliver DO, Wing AJ. Chronic renal failure, dialysis and transplantation. In Weatherall DJ, Ledingham JCG, Warrell DA eds. Oxford textbook Weatherall DJ, Ledingham JCG, Warrell DA eds. Oxford
medicine. 2nd ed. Oxford: Oxford University Press, 1987: 136-8.

17 Kjellstrand CM, Ebben J, Davin T. Time of death, recovery of renal function, development of chronic renal failure and need for chronic haemodialysis in patients with acute tubular necrosis. Transactions of the American Society for Arificial Internal Organs 1981;27:45-50.

(Accepted 27 November 1992) 